\title{
An unusual late sequel to hysterectomy
}

\author{
YANCU HERTZANU \\ M.D.
}

JULIUS HURWITZ M.B., B.Ch.

Department of Diagnostic Radiology, Johannesburg Hospital, Jubilee Road, Parktown 2193, Johannesbu然
Republic of South Africa

\section{Summary}

A case is reported of a large infected foreign body granuloma associated with a retained non-opaque swab presenting 9 years after hysterectomy. An abdominal radiography and whole body computed tomography (CT) scanning demonstrated gas collections in a large abdominal mass. The case underlines the necessity for using radioopaque swabs in all surgical operations.

KEY WORDS: abdomen, foreign body, abscess.

\section{Introduction}

A retained sponge is a well-known post-laparotomy complication. The diagnosis may be readily suspected shortly after surgery. However, when symptoms become apparent years later, the diagnosis may be very difficult.

\section{Case report}

A 51-year-old woman from Greece was admitted for investigation of a large right-sided abdominal mass. No other abnormal physical signs were elicited and she was afebrile. Nine years previously, she had undergone an abdominal hysterectomy. No further surgical intervention had occurred thereafter. Two months before admission, she was investigated for acute epigastric pain and vomiting.

The plain film of the abdomen showed a large soft tissue mass on the right side with numerous gas pockets (Fig. 1). These abdominal gas collections were not present on abdominal X-rays taken 2 months previously. Ultrasound showed a large, welldefined mass lying adjacent to the inferior aspect of the liver and displacing the inferior pole of the right kidney. The mass had a mixed internal echo pattern.

Reprint requests to: Dr Y. Hertzanu, Department of Diagnostic Radiology, Johannesburg Hospital, Private Bag X39, Johannesburg. 2000, Republic of South Africa.

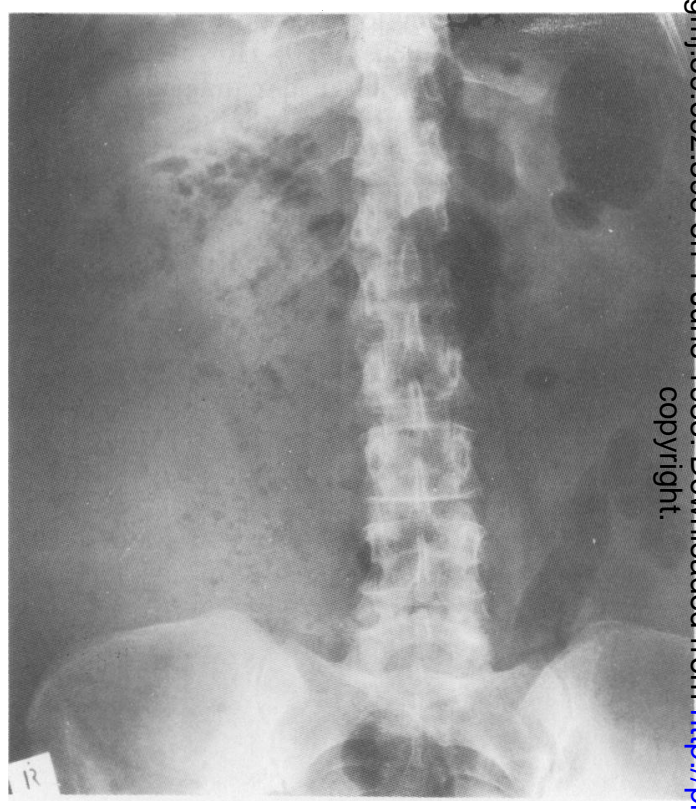

FIG. I. Plain X-ray showing large mass which contains gas bubblèं

The computed tomography (CT) scan showed large low density mass (6-14 $\mathrm{H}$ units) with welt 5 defined margins which enhanced minimally after intravenous contrast injection. The mass contained multiple irregular pockets of gas (Fig. 2).

Correlating these findings with the patient's clinfo cal condition and country of origin, a diagnosis of an infected hydatid cyst was considered.

At laparotomy, a cystic mass, $18 \mathrm{~cm}$ in diamete was found in the peritoneal cavity, partly adherent t\& the liver. It had a smooth outer surface and was easif enucleated. The specimen had a $1.5 \mathrm{~cm}$ thick fibrou capsule with evidence of chronic inflammatory reaction, and the contents were a mixture of fluid ant fibrous material. Histology under polarized ligh showed gauze fibre (Fig. 3). 


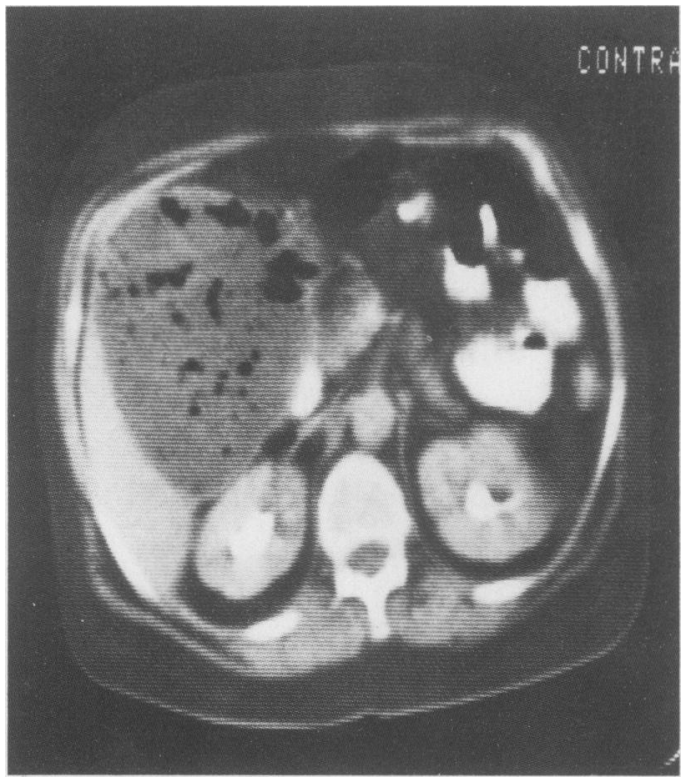

FIG. 2. CT scan, in supine position, showing low density mass closely applied to the liver. Numerous air pockets are present within the mass.

\section{Discussion}

Fragments of gauze introduced at operation may result in foreign body granuloma formation. This has been confirmed experimentally (Sturdy, Baird and Gerein, 1967). Most patients with a retained sponge develop complications within weeks or months. The inflammatory response to the foreign body may be either an exudative or an aseptic fibrinous form (Olnick, Weens and Rogers, 1955; Wells, Hyun and Mitchell, 1963). The exudative form results in abscess formation. The aseptic fibrinous form results in encapsulation following on low grade inflammatory reaction. It may gradually increase in size and present as a tumour or be an incidental finding at laparotomy (Carsky and Haswell, 1978). This is the most common form encountered when the sponge has been retained for more than 5 years.

Sponges are easily detected on X-ray if they contain radiopaque markers (Williams, Braagg and Necson, 1978). Gas trapped between the fibres gives a characteristic whorl-like configuration. Differential diagnosis of the gas pockets on plain X-ray include a pyogenic abscess and a faecaloma. The gas was probably due to infection by gas-forming aerobic enteric bacteria.

Ultrasound features in cases of foreign body granulomata, with thick irregular echo boundaries and irregular internal echoes, have been described

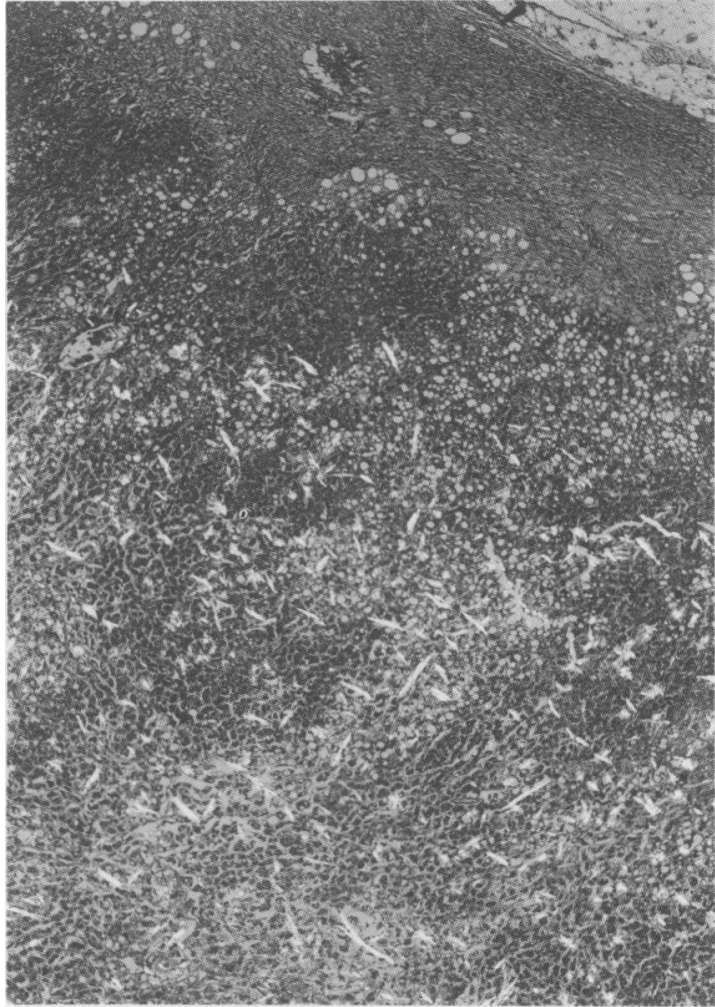

FIG. 3. Microscopic examination of specimen under polarized light showing foreign bodies consistent with gauze fibres.

(Sekiba, Akamatsu and Niwa, 1979). A previous report has described the CT appearance following retained surgical sponges (Parienty et al., 1981).

The differential diagnosis of an infected foreign body granuloma should be included in patients with a history of previous abdominal surgery who present with a mass which contains pockets of gas on X-ray examination.

\section{Acknowledgment}

We wish to thank Professor J. I. Levy for useful comments and criticism.

\section{References}

CARSKY, E.W. \& Haswell, D.M. (1978) Huge laparotomy pad granuloma simulating a gastric wall tumour. American Journal of Roentgenology, 131, 909.

OlNICK, H.M., WeENS, H.S. \& Rogers, J.V., JR. (1955) Radiological diagnosis of retained surgical sponges. Journal of the American Medical Association, 159, 1525.

Parienty, R.A., Pradel, J., Lepreux, J.F., Nicodeme, Ch. \& DologA, M. (1981) Computed tomography of sponges retained after laparotomy. Journal of Computer Assisted Tomography, 5, 187.

Sekiba, K., Akamatsu, N. \& Niwa, K. (1979) Ultrasound charac- 
teristic of abdominal abscesses involving foreign bodies (gauze). Journal of Clinical Ultrasound, 7, 284.

Sturdy, J.H., BaIRD, R.M. \& Gerein, A.N. (1967) Surgical sponges. A cause of granuloma and adhesion formation. Annals of Surgery, 165, 128.

Wells, H.A., HyUN, B.H. \& Mitchell, R.E. (1963) A retained surgical sponge with interesting sequels. American Journal of Medicine, 35, 423.

Williams, R.G., BRaAgG, D.G. \& Necson, J.A. (1978) Gossypi-C. boma-the problem of the retained surgical sponge. Radiology 128, 323.

(Accepted 9 September 1982) 